\title{
An Activity Promoting the Practice of Quantitative Literacy for Pre- and In-Service Teachers of Mathematics and Science
}

Timothy L. Sorey

Chemistry Department and Science Education Department, Central Washington University, Ellensburg WA, soreyt@cwu.edu

Teri Willard

Mathematics Department, Central Washington University, Ellensburg WA, penmont@charter.net Duane Sholz

Undergraduate Chemistry Major, Central Washington University, Ellensburg WA

Follow this and additional works at: https://digitalcommons.usf.edu/numeracy

Part of the Mathematics Commons, and the Science and Mathematics Education Commons

\section{Recommended Citation}

Sorey, Timothy L., Teri Willard, and Duane Sholz. "An Activity Promoting the Practice of Quantitative Literacy for Pre- and In-Service Teachers of Mathematics and Science." Numeracy 3, Iss. 1 (2010): Article 6. DOI: http://dx.doi.org/10.5038/1936-4660.3.1.6 


\title{
An Activity Promoting the Practice of Quantitative Literacy for Pre- and In-Service Teachers of Mathematics and Science
}

\begin{abstract}
The purpose of this article is to describe a hands-on, laboratory activity that provided pre-service teachers in mathematics and science methods courses, and also some in-service mathematics teachers, with the opportunity to exercise quantitative literacy (QL) skills. The focus of the activity is electrical resistance, more particularly the resistance (in ohms) that is painted on small resistors by the use of color-coded bands, one of which is a band for \% error. The activity consists of four parts. In the first, student teams familiarize themselves with the code, measure the ohmage of resistors for which the codes are visible, and compare their measurements with the labels. In the second part of the activity, the teams measure the ohmage of many resistors-all from the same batch-on which the code bands have been covered. In the third part, they decide what statistics to use to determine the code bands that should be on their resistors, make poster presentations of their predictions, and then compare their predictions with the actual label. At the end of the third part of the activity, the student teams discover that their predictions do not match the labels, and they are placed in a cognitive conflict. In the fourth part of the activity-the QL part-they integrate what they have learned about the nano-, micro-, and macroscopic structure of resistors and the statistical measures that they used with what they can find out about marketing practices to present a written argument explaining the discrepancy. Pre- and post-tests show that students learn statistical and resistor material associated with the activity, and qualitative assessment of their written explanations of the discrepancy show that students had various levels of success at integrating their mathematical understanding with the science and business context of this measurement activity.
\end{abstract}

\section{Keywords}

quantitative literacy, teacher education, integrated curriculum, statistics, mathematics, chemistry, electronics, marketing

\section{Creative Commons License}

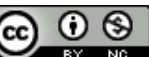

This work is licensed under a Creative Commons Attribution-Noncommercial 4.0 License 


\section{Introduction}

“Hey, man. How's it goin'?" (pause) "Oh, me, just waitin' for class. See ya later."

Recognize this? How many times a day do you hear a one-sided conversation on a cell phone? From cell phones and computers to self-dimming rearview mirrors and car stereos, almost every modern device requires circuitry to operate. One essential component of electronic circuits is the resistor.

What, you might ask, do electronic resistors have to do with quantitative literacy $(\mathrm{QL})$ ? The purpose of this article is to describe a hands-on QL-enhanced activity within a complex setting involving the chemistry, measurement, statistics, and pricing of electronic resistors (Fig 1). We provide materials for readers who may wish to use this activity in a course. We also present some results from our using the activity.

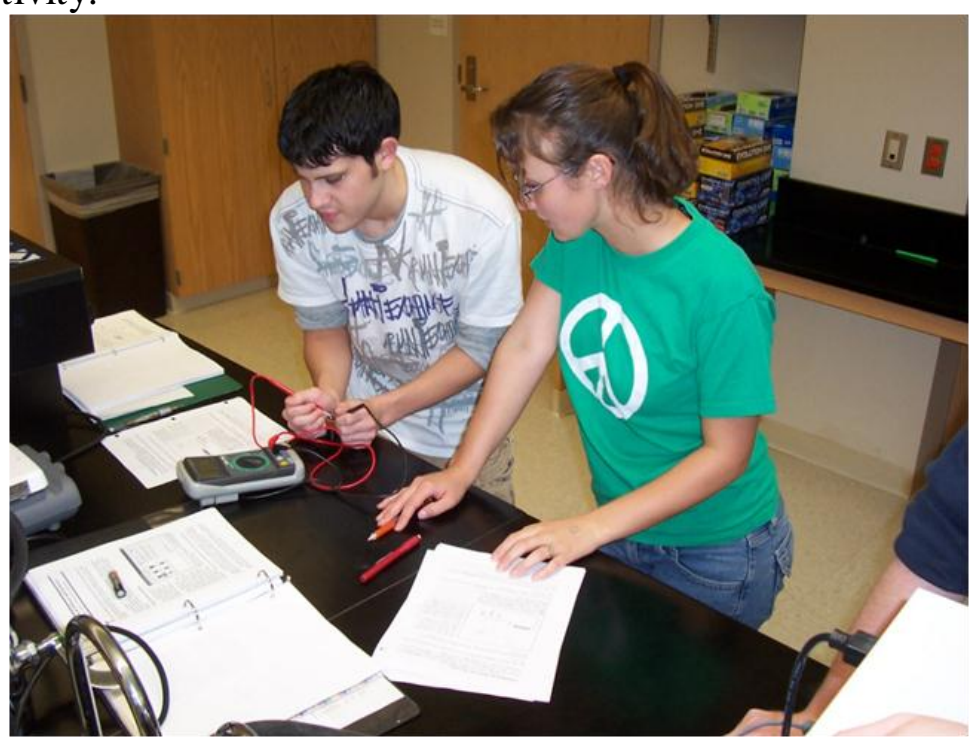

Figure 1. Students measuring resistors with digital multimeters.

The authors of this article include a mathematics education professor and a chemical education professor at Central Washington University in the Pacific Northwest. We team teach secondary and middle school mathematics and science methods courses for pre-service teachers. We have refined and piloted the activity described here over the past five years in methods courses for pre-service middle school teachers and high school mathematics and science teachers. Some inservice high school mathematics teachers at a national mathematics convention have also engaged in a portion of the activity. ${ }^{1}$

${ }^{1}$ For convenience, all participants in the activity will be referred to as "students" whether preservice or in-service teachers. 
For the purposes of this article, we will use this definition for QL (Wilkins 2000, p 405-406): "Quantitative literacy includes knowledge of mathematical content embedded in a contextual framework that promotes an understanding and appreciation of the nature, development, and social impact of its applications." We interpret this definition of QL to include an ability to make and support arguments using quantitative evidence in the context of solving a real-world problem (Madison and Steen 2009).

When we began with the activity we describe here, our intent was to create a hands-on integrated mathematics and science inquiry-based activity, using informal quizzes and surveys to determine whether the activity was worthwhile and should continue to be used in our methods course. At that time, we acquired, analyzed, and compiled classroom assessment data without a working knowledge of current thinking in QL. As the years passed and we continued to review the student assessment data, the activity not only began to more "smoothly integrate" mathematics and science, but as the lesson evolved it became apparent that students needed to consider implications in both chemistry and pricing of resistors to solve a puzzle that emerges from the data that students collect during the activity (Pienta and Amend 2005; Sorey and Amend 2005). Smoothly integrated to us meant that neither the science nor the math could survive alone nor drive the activity independently. As we continued to use the activity, we were finally led to recognize that the activity was not just integration of math and science, but did, in fact, revolve around the basic tenets of QL.

How did the authors come to identify this activity as promoting QL? The answer to this question lies in the fact that our university has been delving into the discipline and, specifically, has been offering mathematics courses designed to develop QL skills. One of us has taught such a course several times over the past five years. In addition, a colleague in the mathematics department introduced us to the journal Numeracy. Upon reading issues of the journal, consulting with this colleague who had published in the journal and presented at a QL conference, and examining QL modules posted ${ }^{2}$ on a Web site of the Washington Center for Improving the Quality of Undergraduate Education, one of the original institutions of the National Numeracy Network (Madison and Steen 2008), we realized that our activity was more than integrated mathematics and science (Boersma and Willard 2008). Reading the following passage ${ }^{3}$ from an explanatory page of that module collection convinced us that we had found the niche for our own activity, namely QL.

\footnotetext{
2 Vacher (ca. 2004), "Modules for Geological-Mathematical Problem Solving." http://www.evergreen.edu/washcenter/modules/start.htm (accessed Dec. 12, 2009).

3 Vacher (ca. 2004), "Quantitative Literacy" http://www.evergreen.edu/washcenter/modules/home.asp (accessed Dec. 12, 2009).
} 
Quantitative literacy (QL) is the habit of mind in which one engages numbers in everyday context. It is an attitude, a disposition. It is the opposite of the condition manifested by math anxiety, math phobia, and math avoidance. QL involves elementary mathematics. It is mathematics for all students. It is mathematics all citizens can use. Using mathematics is proactive, not passive. Using mathematics means solving problems not just exercises at the end of a chapter on a set of mathematical relationships, but problems that come outside the mathematics building and beyond reach of the mathematics book.

(See Madison and Steen 2008 for more about the history of QL and numeracy and Mast 2009 for current interpretations of QL.)

We have asked ourselves, "Why should mathematics and science educators care about including QL in their curricula?" From the mathematics side, the National Council of Teachers of Mathematics' Principles and Standards for School Mathematics Executive Summary contains language associated with QL (NCTM 2000 p.2).

We live in a time of extraordinary and accelerating change. New knowledge, tools, and ways of doing and communicating mathematics continue to emerge and evolve. The need to understand and be able to use mathematics in everyday life and in the workplace has never been greater and will continue to increase.

On the science side, George D. Nelson, a previous director of Project 2061, a national initiative of the American Association for the Advancement of the Science to reform $\mathrm{K}-12$ science, mathematics, and technology education, believes that QL is part of exemplary science teaching practices and "...exists in many places but always in specific contexts. Yet for lack of appropriate contexts, QL rarely is seen in school classes" (Nelson and Steen 2003, p 179-180).

In the activity described in this article, students use measurement technology to collect their own data, use mathematics to analyze the results, and make arguments and data-driven conclusions about a puzzle that emerges from their experimental results, thus supporting the basic tenets of QL. Before beginning the activity, students need instruction in the basic chemistry and manufacturing of resistors in order to solve the QL puzzle that emerges in the latter part of the activity. Knowledge of the chemical composition of resistors is crucial for a contextual framework that promotes the QL, as well as for the reader to fully understand the activity.

\section{Background Chemistry Information}

For students to understand how carbon composition resistors function, they require knowledge from three different scales that starts at the nanoscopic $\left(1 \times 10^{-9}\right.$ 
$\mathrm{m})$, proceeds to the microscopic $\left(1 \times 10^{-6} \mathrm{~m}\right)$, and finishes at the macroscopic $\left(>1 \times 10^{-3} \mathrm{~m}\right)$. Students must start at the nanoscopic scale of graphite particles to understand that carbon-carbon double bonds facilitate the flow of electrons (electrical conduction). At the microscopic scale, students need to know that graphite and silica sand create a composite material that resists the flow of electricity (electrical resistance). Finally, it is imperative that students understand the macroscopic components of a resistor so that they can comprehend how the resistor functions as a part of an electrical circuit and how to identify color coding that represent units of electrical resistance.

At the nanoscopic level, benzene and graphite have planar configurations that contain six-member carbon-carbon rings with double bonds (Fig. 2). In benzene and graphite, a third dimension to the structure exists above and below these carbon-carbon ring planes, namely dumbbell-shaped electron orbitals ( $p$-orbitals). These $p$-orbitals are populated with electrons, $\boldsymbol{e}^{-}$, as shown in Figure 3 for benzene.
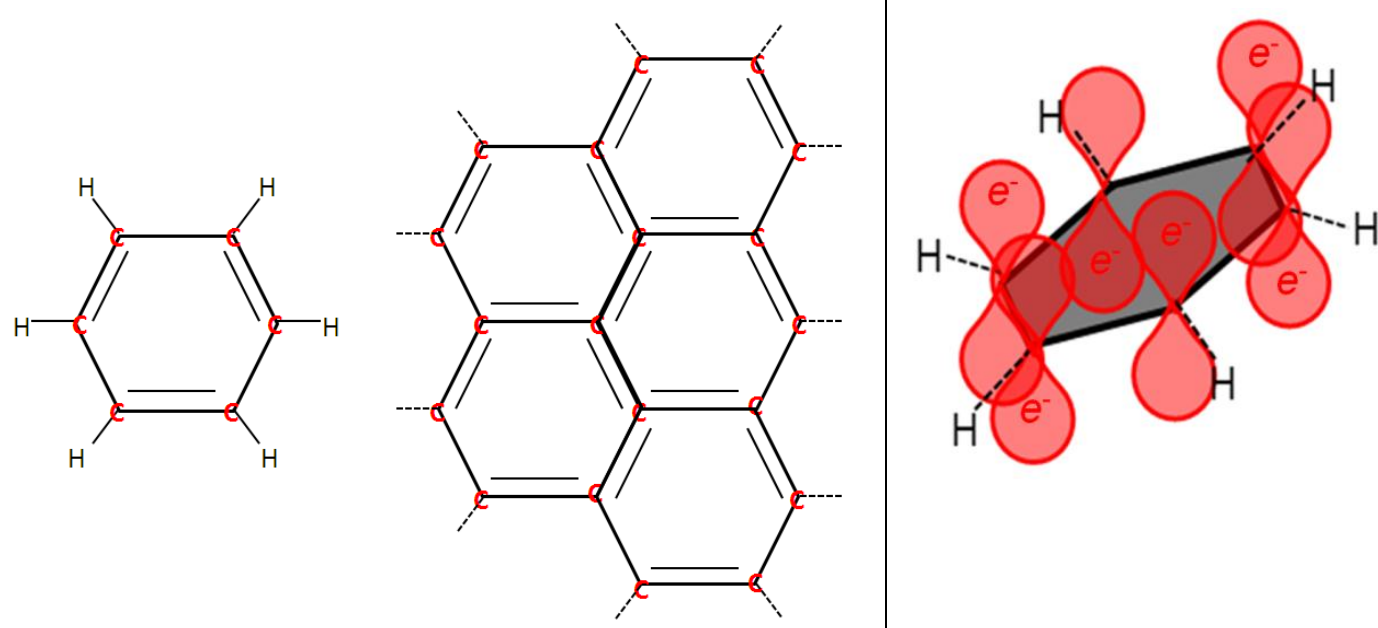

Figure 2. Benzene (left) and graphite (right) are

Figure 3. Benzene contains composed of six-member carbon-carbon rings.

dumbbell shaped $p$-orbitals.

In graphite, the $p$-orbitals above and below the planes of carbon nuclei are arranged in such a way that the planes of carbon are loosely attracted to each other. These "loose attractions" cause a network of contiguous planes of carbon to stack on top of one another, much like various layers of egg cartons stack upon one another at the grocery store (Fig. 4). Accordingly, graphite carbon is referred to as a network-covalent solid (Brown et. al. 1998). When placed between the negative ( - ) and positive (+) terminals of a battery, graphite allows electrons to flow freely across its $p$-orbitals, a phenomenon also known as electrical conduction (Hill and Horowitz 1989). 


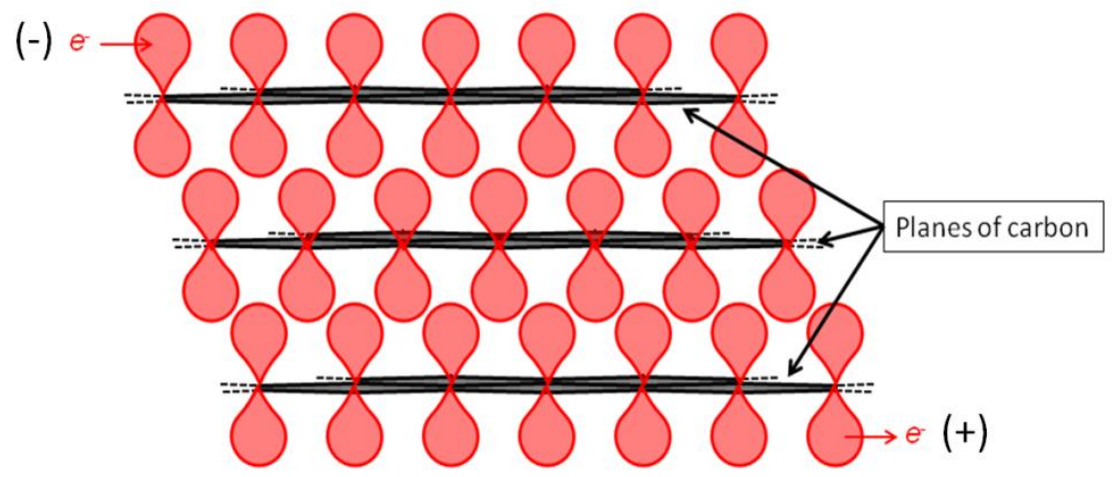

Figure 4. The $p$-orbitals of graphite stack on top of one another, easily conducting electricity throughout the solid.

At the microscopic level of graphite carbon composition resistors, powdered graphite carbon and silica sand are placed into a small chamber. Packing and baking these materials at high temperatures cause some of the conductive graphite particles to come into physical contact with one another, making sintered contacts, while the heating causes the non-conductive silica sand to melt and fill into gaps where the graphite particles don't touch, making insulating contacts (Fig. 5). Sintered contacts between graphite particles allow electrons to conduct through the composite material while insulating contacts of the melted silica sand resist the flow of electrons. This is why the graphite and silica composite material is commonly referred to as a resistor (Hill and Horowitz 1989).

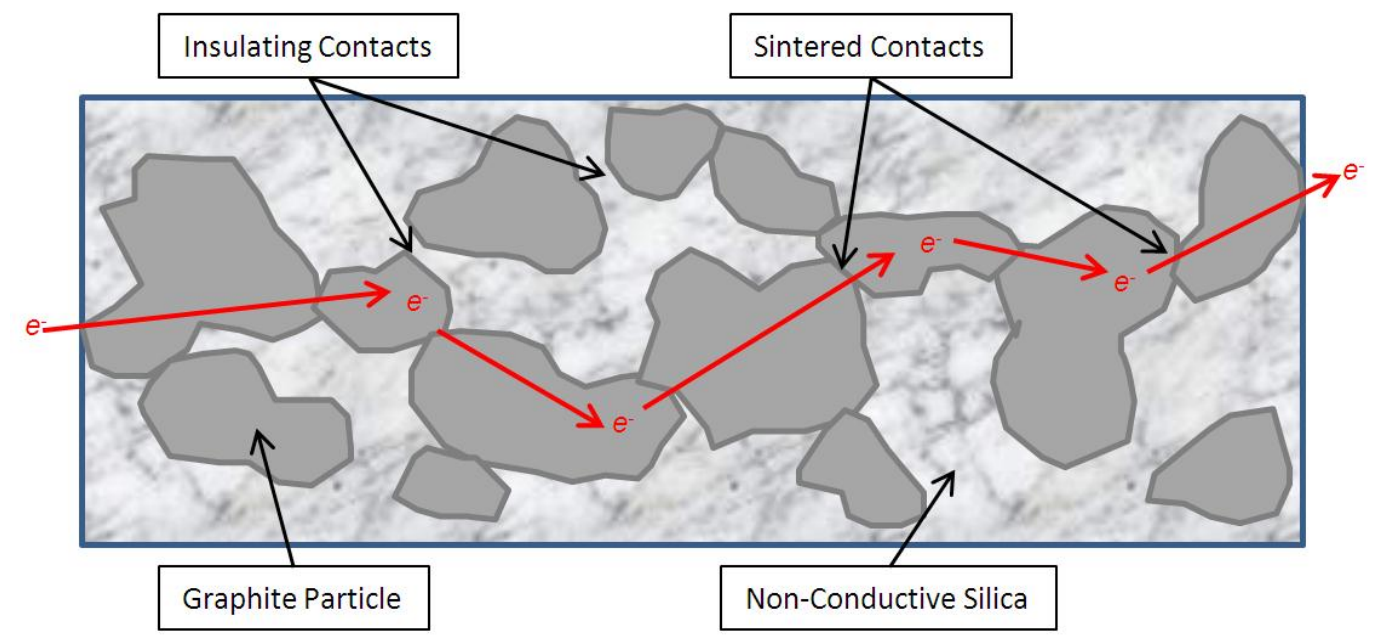

Figure 5. Packed and baked graphite/silica material creates electric pathways.

At the macroscopic level, the carbon composition material is placed between two conductive metal leads and encased in a non-conductive plastic epoxy body so that it can be soldered into an electrical circuit. Manufacturers test the resistor 
for a resistance value in units of ohms, $\Omega$, and then paint an Electronic Industry Alliance (EIA) color code on the epoxy body for identification (Fig. 6).

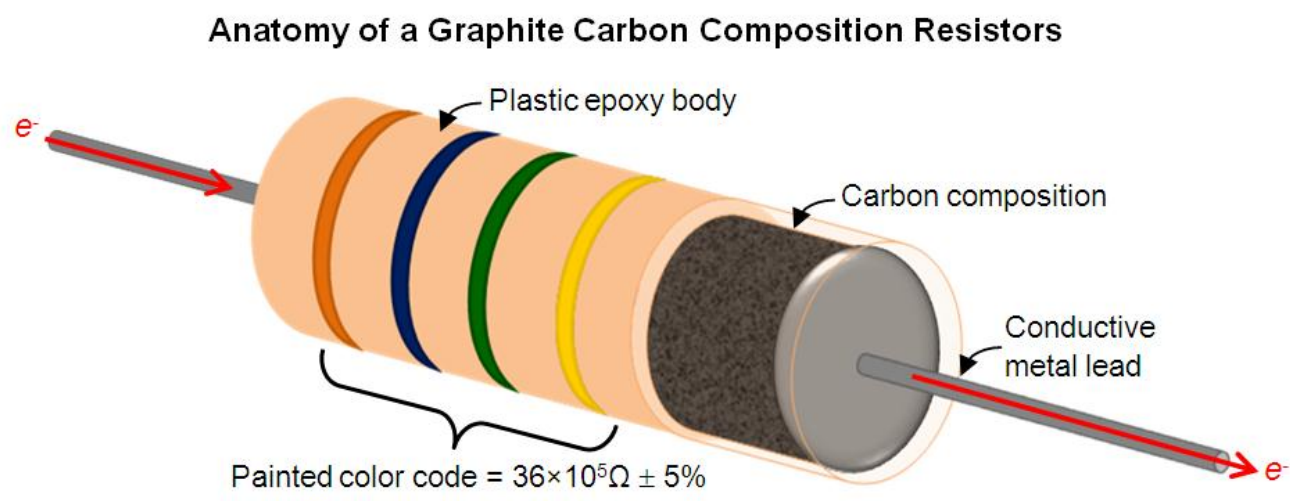

Figure 6. Anatomy of a carbon composition resistor

As with most physical science theories that pertain to the sub-macroscopic world, conceptualization of how electricity flows requires students to have a bit of imagination, which oftentimes benefits from an interactive discussion with the instructor. The chemical knowledge presented in this section, therefore, is crucial underpinning for contextual framework that enables the QL in the upcoming hands-on student activity.

\section{The Activity}

In this section we present the activity in which students are engaged. For more details, please see the appendices. Lesson plans and student hand-outs are in Appendices A and B, respectively. You may also consider assessing the level of your students' knowledge of descriptive statistics beforehand. In our implementation, the activity was combined with material on the basics of statistical measures.

We purchased 1/4-watt, through-hole carbon composition resistors from the electrical engineering program at our university. We used a mix of single resistors with different painted color code values (Fig. 6) in Part 1 of the activity and twohundred resistors from a manufacturer's batch of 1,000 resistors with the same painted color code (Fig. 7) for the rest of the activity. The singly bought resistors were about 10 cents each while the bulk resistors cost about 1.1 cents, adding up to a total cost of less than $\$ 10$. This type of carbon composition resistor is also easily purchased in batches off the assembly line at the local electronics store, although you might find it cheaper to purchase them through any number of online vendors, such as JAMECo.com, Digikey-key.com, or Newark.com. 


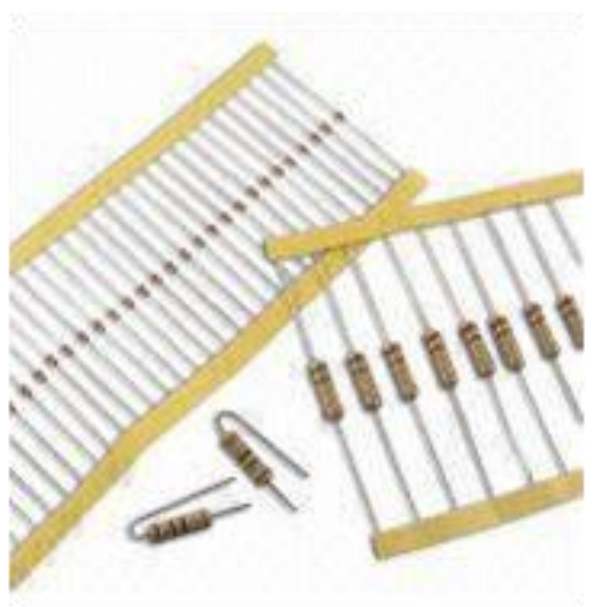

Figure 7. Carbon composite resistors can be purchased in rolls of 100 or more.

Each part of the resistor activity begins with a guiding question that supports the inquiry-based nature of this QL-enhanced activity. During the entire activity, including our assessment, the students worked in either pairs or small groups (Vygotsky 1962).

\section{Part 1: What does the color code on a resistor mean?}

Groups of students received a plastic baggie containing five resistors each with a different sequence of colored bands. They also received an EIA resistor chart (Fig. 8).

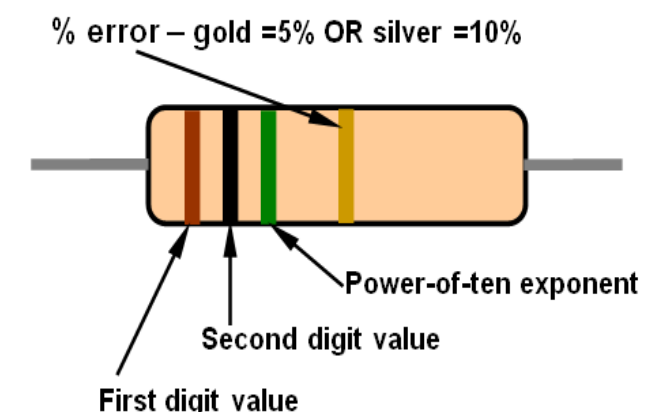

Color:brown black green gold $(5 \%)$ This resistor's value Value: $105+/-5,000 \Omega=10 \times 10^{5} \Omega \pm 5,000 \Omega$

\section{Color coding a resistor}

$\begin{array}{lcc}\frac{\text { Color }}{\text { black }} & \frac{\text { Value }}{n} & \frac{\text { Exponent }}{10^{0}} \\ \text { brown } & 1 & 10^{1} \\ \text { red } & 2 & 10^{2} \\ \text { orange } & 3 & 10^{3} \\ \text { yellow } & 4 & 10^{4} \\ \text { green } & 5 & 10^{5} \\ \text { blue } & 6 & 10^{6} \\ \text { violet } & 7 & 10^{7} \\ \text { grey } & 8 & 10^{8} \\ \text { white } & 9 & 10^{9}\end{array}$

Figure 8. Resistor chart.

As instructors, we helped students interpret the chart. The first two bands from the left are the first and second significant figures. The third band is the power-of-ten 
exponent for the multiplier (see "Color coding" table in Fig. 8). The fourth metallic colored band indicates percent error, where silver and gold indicate $10 \%$ and $5 \%$ error, respectively.

For example, the resistor shown in Figure 8 with brown, black, and green colored bands has value:

brown-digit value (1), black-digit value (0), $\times 10^{\text {green-digit value exponent (5) }} \Omega$

or

$$
10 \times 10^{5} \Omega=1,000,000 \Omega=1.0 \mathrm{M} \Omega
$$

Using the resistor chart, students predicted the ohmage of each of their five resistors. After students recorded the color code and wrote numeric predictions, they used a digital multimeter (DMM) to measure resistance to three significant figures (Fig. 9 and Fig. 10).

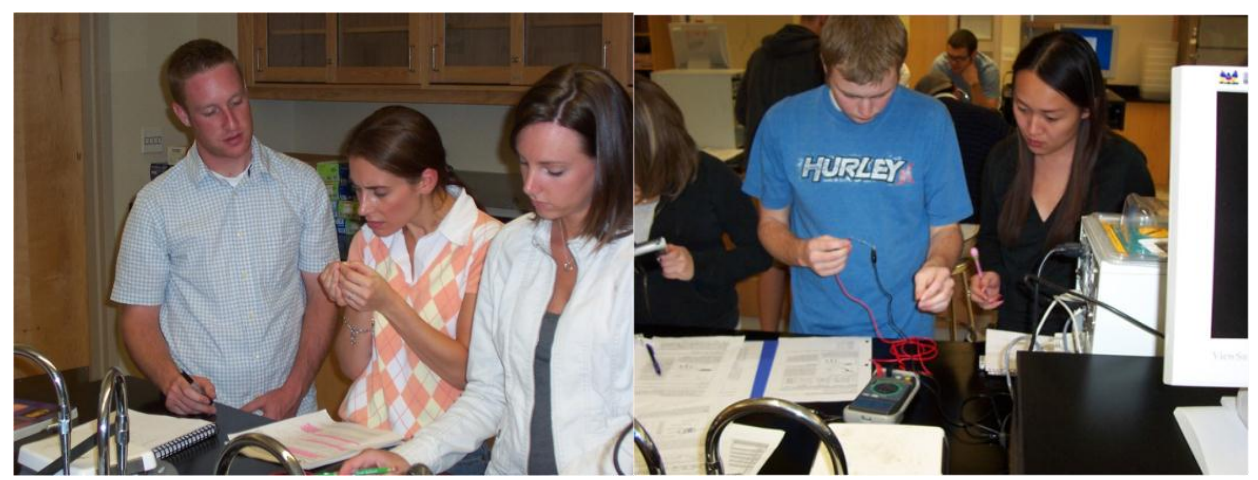

Figure 9. (a) Students decipher color codes and then (b) measure the ohmage of the resistors with DMMs.

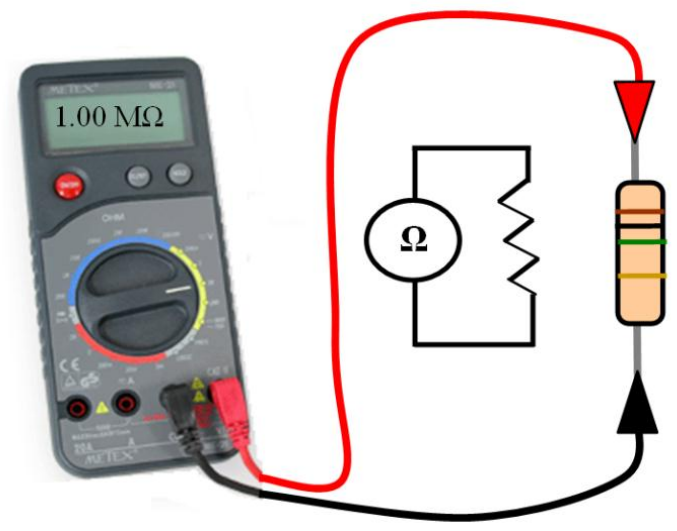

Figure 10. Resistor measurement with a DMM. 
Finally, students checked the fourth band using the \% error formula:

$\%$ error $=[($ measured value - predicted value $) /($ predicted value $)] \times 100 \%$

Typical resistor data are shown in Table 1.

Table 1

Sample Resistor Data from Five Resistors

\begin{tabular}{cllcl}
\hline Resistor & Resistor color code & $\begin{array}{l}\text { Predicted } \\
\text { value }(\Omega)\end{array}$ & $\begin{array}{l}\text { Measured } \\
\text { value }(\Omega)\end{array}$ & $\begin{array}{l}\text { Calculated } \\
\text { error }(\%)\end{array}$ \\
\hline 1 & brown, green, yellow, gold & $15 \times 10^{4}$ & 149,000 & -0.667 \\
2 & orange, orange, orange, silver & $33 \times 10^{3}$ & 30,200 & -8.48 \\
3 & brown, black, red, gold & $10 \times 10^{2}$ & 1,010 & +1.00 \\
4 & blue, grey, brown, silver & $68 \times 10^{1}$ & 637 & -6.32 \\
5 & brown, black, brown, gold & $10 \times 10^{1}$ & 99.2 & -0.800 \\
\hline
\end{tabular}

Students realized that the painted color code did not exactly match the first two digit values, but did match the power-of-ten multiplier and the percent error. This illustrated to them the variability always present in resistors.

\section{Part 2: What color bands are on our resistors?}

For this part of the activity, we cut about 30 resistors from the roll of resistors we had purchased with identical painted color bands, and placed them in a baggie. Then we cut about 30 more and did the same, repeating until we had enough baggies of resistors for all of our groups. Although students were told that all the resistors in the class had an identical color code, black electrical tape was placed on the resistors' epoxy bodies. The students were challenged to determine all four of the EIA color code bands experimentally before they could remove the tape and check their predictions.

First, the students measured the ohmage of each resistor and recorded each value to three significant figures. Next, the groups brainstormed and decided which statistics would best represent their resistor data. Then, they made posters displaying statistics, graphs, and their predictions of the color code.

\section{Part 3: What do statistics say about resistor color codes?}

At the beginning of this part of the activity, groups presented their posters with statistics and graphs to represent their resistors. We expected most students to use mean and standard deviation, but some students chose also to report the range, median, and mode. Student graphs ranged from scatter plots to box plots to bar graphs or histograms. Each time we presented the activity, we found that several groups decided to pool their data for a graph of more data points. 


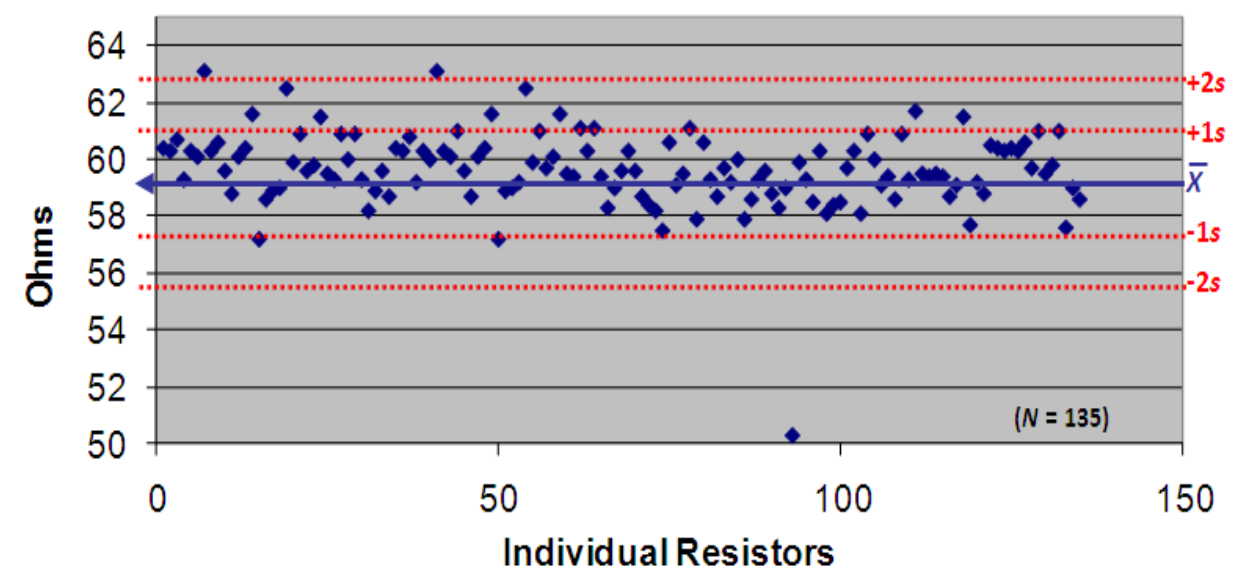

Figure 11. Scatter plot of 135 resistors displaying the mean, $\bar{x}, \pm$ one standard deviation (1s), and \pm two standard deviations $(2 s)$.

Figure 11 shows a sample student graph, a scatter plot, created from pooled data for a total of 135 resistors. In this graph, students assigned each resistor a number, graphed on the horizontal axis, and then recorded the measured resistancce of each resistor, in ohms, on the vertical axis. For example, if resistor number 1 had a resistnace of $61.5 \Omega$, then the ordered pair graphed for that resistor would be $(1,61.5)$. The students in this combined group found that the mean, $\bar{x}$, of their data was $59.6 \Omega$ with a standard deviation, $s$, of $1.38 \Omega$. As instructors, we had observed this graph being constructed and had actively guided the students to mark these values on their graph with dotted horizontal lines as seen in Figure 8.

Another group of students created a graph, Figure 12, using the same pooled data of 135 resistors. In this graph, the data were binned into equal-sized categories and then a graph similar to a bar graph was constructed. For example, in the bin for 57.5-57.9 $\Omega$, there were five resistors. Again, as facilitators in this cooperative instructional classroom setting, we observed the students constructing this graph and suggested that they manually draw lines and textboxes that showed one and two standard deviations from the mean, as shown in Figure 12.

After student groups finished presenting the graphs and statistics for their set of resistors, we found that most students were ready to assign the colored bands of blue, black, and black, representing $60 \Omega$, to their resistors since 59.6 rounds to 60. However, there was still the fourth band to consider. We could have easily instructed students in our own methods for finding the color of the fourth band, but we resisted and asked students to brainstorm to assign the color for this final band. 


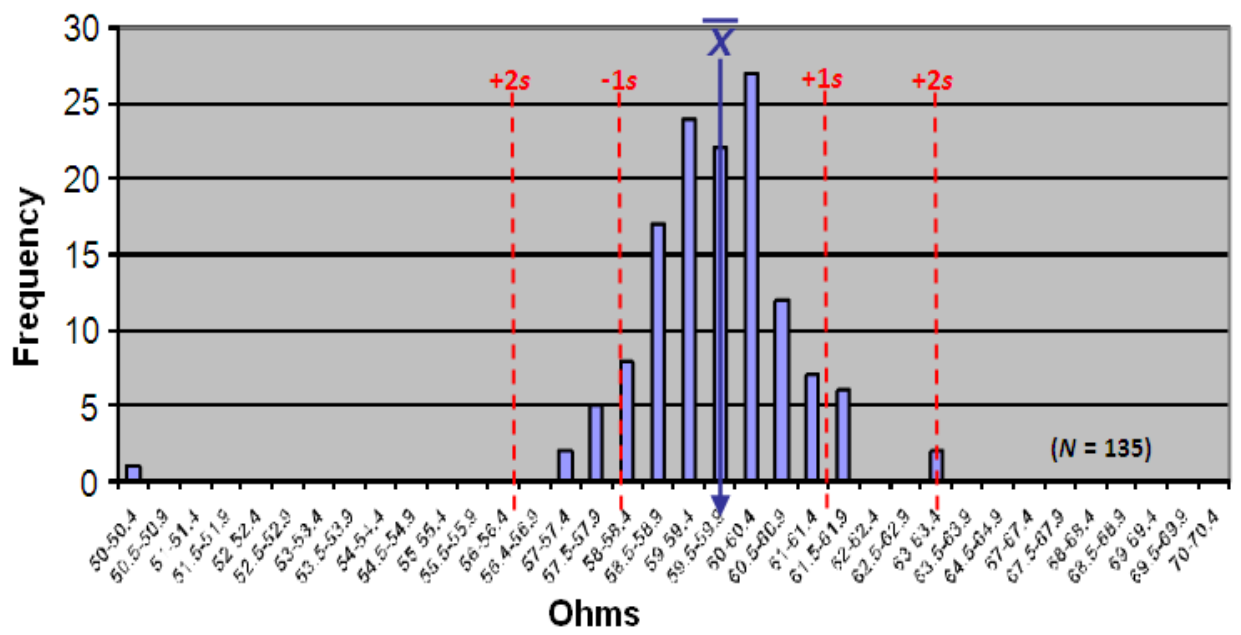

Figure 12. Frequency of resistors in each $0.5 \Omega$ bin, marked with mean and one and two standard deviations of the mean.

Some students struggled, some seem paralyzed in determining a method to find the percent error. However, as instructors, we were observing the groups and asking questions to help them refine their ideas and reach a satisfactory method. The method that arose most often was to look at the entire data set, eliminate any resistor measurements that were outliers, and then calculate a percent from the remaining furthest points. For example, in Figure 12, one can see that the data point located in the 50.0-50.4 bin is far from the other data. So, with this outlierelimination method, one would eliminate that resistor as being some type of exception, such as a resistor that was not caught by quality control in the factory. Next, notice that there are two resistors in the 63.0-63.4 category, which is not too terribly far from the rest of the data. Now, assuming that the resistors in this bin measured $63.2 \Omega$, find the difference of 63.2 and the mean (59.6), or $63.2-$ $59.6=3.6$. Next, find the percent that 3.6 is of the mean: $(3.6 \div 59.6) \times 100 \approx 6 \%$. Because $6 \%$ is closer to $5 \%$ than $10 \%$ and the $63.2 \Omega$ resistor may also have slipped by in a quality control inspection, the last band would be gold for $5 \%$. Therefore, the bands on the set of resistors present in the classroom would be blue, black, black, and gold (see "Color coding" table in Fig. 8).

In all problem-solving situations, it is always better to have several methods of solving a problem. As instructors, we had our own method in mind. After students shared their methods, we shared ours. Our method was based directly upon the mean, standard deviation, and percent relative standard deviation 
(\%RSD), which is used by analytical chemists to determine percent error that is relative to statistical mean.

To set the class up for this method, we started by giving groups a copy of the graph shown in Figure 12. Students counted the number of resistors within one standard deviation of the mean. They reported about 95 resistors, or $70.4 \%$, of the total resistors in this region. Students then counted resistors within two standard deviations of the mean and found about 133 resistors, or $98.5 \%$, of the total resistors in this region. The students' experimental values aligned well with data that are normally distributed about the mean, where about $68 \%$ of the values will be within $\bar{x} \pm s$, and about $95 \%$ of the data will be within $\bar{x} \pm 2 s$ (Skoog et al. 1998).

Next, students learned more about \%RSD. This value is calculated by dividing the standard deviation by the experimental mean of the resistors and multiplying by 100 . For the graph in Figure 12, the calculation of one $\%$ RSD is:

$$
\text { one } \% \operatorname{RSD}=[(1.38 \Omega / 59.6 \Omega) \times 100] \% \approx 2.31 \%
$$

of the mean and so, two \%RSDs are $2 \times 2.31 \%$, or $4.63 \%$ of the mean. This means that about $98.5 \%$ of the resistors, as counted by the students, were within the range of two \%RSDs. Now students were seeing the light. With the help of Figure 13 , students realized that about $98.5 \%$ of the resistor data were within $\bar{x} \pm 2 s$, which is $59.6 \Omega \pm 4.63 \%$ The \%RSD method thus validated the answer derived by the students' method, suggesting a $5 \%$ error.

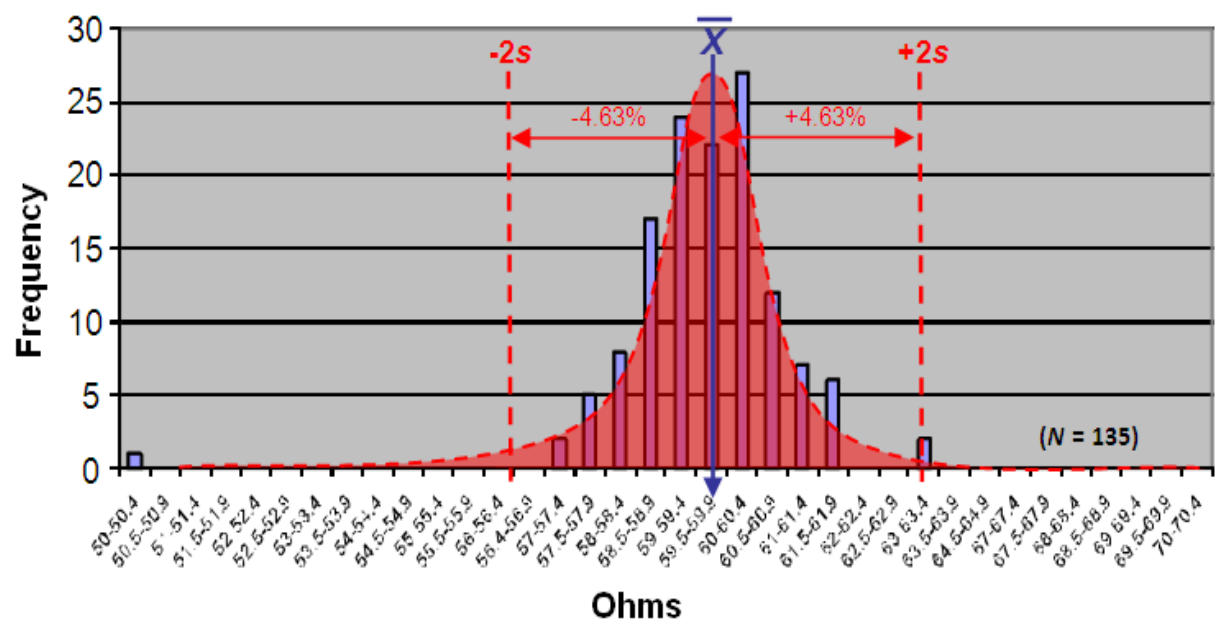

Figure 13. $98.5 \%$ of the resistors are contained within $2 s$; therefore, they are within two \%RSD or $4.63 \%$ of the mean of $59.6 \Omega$.

As students examined their method of finding the color of the fourth band and our method, they began tying abstract math concepts to this real sample of resistors. As instructors, we felt that giving students an opportunity to problem 
solve in cooperative groups to predict the color of the bands had paid off in improved understanding and satisfaction for the students. However, the students were not happy for long.

At the end of this part of the activity, students were allowed to peel back the black electrical tape to see if their collective prediction of blue, black, black, and gold was correct. In every classroom, students were appalled when they ripped back the black tape to reveal that the painted color bands were green, blue, black, and silver, representing a resistor of $56 \times 10^{0}$ ohms $\pm 10 \%$.

Predicting an actual value from experimentally collected values, but not having it validated, placed students in a cognitive conflict (Bruner 1960). Students were puzzled and cried, "What is going on? Were our calculations wrong? Was our experiment flawed? What is a reasonable explanation for this inconsistency?"

\section{Part 4: Is this painted color code valid for our resistors?}

To help students in their quest to find some resolution to this inconsistency, we provided each group the graph from Figure 12, without the mean and standard deviation markings. We asked them to mark where $56 \times 10^{0} \Omega \pm 10 \%$ would be located on their graphs. Then we provided Figure 14 for clarification. From this, students observed that even though the mean painted on the resistors did not match their experimentally determined mean, about $93.3 \%$ of the resistors did, in fact, fall within $\pm 10 \%$ of the actual value in ohms painted on the resistors. Faced with the evidence, they begrudgingly agreed that green, blue, black, and silver was a plausible color code for their resistors.

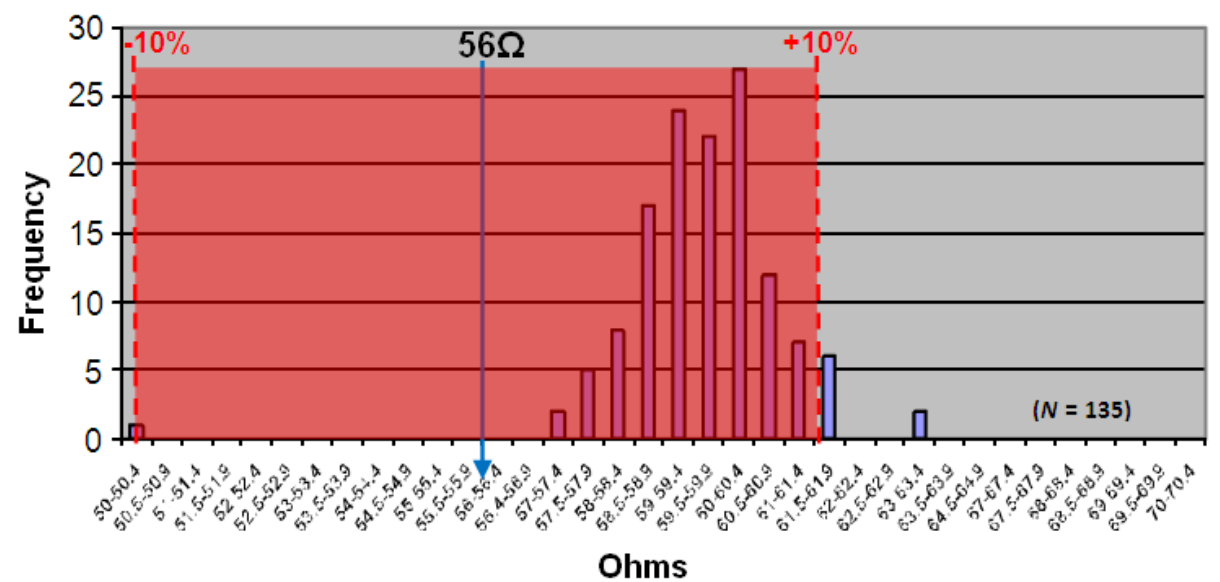

Figure 14. Actual color code painted on the resistors, $56 \Omega \pm 10 \%$.

Our students were now ready for their final task - explaining the discrepancy between their prediction and the actual markings on the set of resistors 


\section{Part 5: Why doesn't our prediction match the color code?}

Now was the time for the final assessment for the resistor activity. We consider this assessment to be an actual part of the activity because students began working on this project in class. This project was more than just an assessment, however. It provided the students with the opportunity to synthesize everything they had learned up to this point with new information from their own research and apply QL skills in support of an argument (Madison and Steen 2009).

In this project, students needed to explain the discrepancy between the measured resistor value suggested by the experimentally determined mean and standard deviation, and the actual painted color bands that were painted onthe resistors. Recall that the student calculation of the mean and standard deviation of the resistor data set and graphs implied that the resistors should be $60 \Omega$ resistors with an error of $\pm 5 \%$. However, the painted colored bands actually identified the resistors as $56 \Omega$ with an error of $\pm 10 \%$.

For the project paper, students needed to follow these guidelines:

- An argument should be clearly stated that explains the discrepancy.

- The argument should be both explained and supported using all four of the following criteria:

1. scientific understanding of resistors,

2. the experimental statistical data,

3. at least one appropriate graph, and

4. the pricing of the resistors with a source included and cited.

- The paper should have logical flow with clarity about the situation.

- The paper should be typed, containing few or no errors in grammar, spelling, and/or punctuation, and should be easy to read.

In the next section of this article, we present and discuss data gathered for the purpose of assessing student learning. Recall that the students participating in this activity included both pre-service mathematics and science teachers and inservice teachers attending a workshop at a national mathematics conference.

\section{Assessment of Student Learning}

In this section, we report both quantitative and qualitative assessment data. Quantitative assessments were pre- and post- quizzes. Qualitative assessments were the written projects. These quizzes and written projects were designed to assess critical factual math and science knowledge. In this activity, factual mathematical and scientific knowledge are crucial when making a convincing data-driven argument. At our university, the middle school and secondary mathematics and science methods courses are offered once per year, so the number of students participating was relatively small. Of the 59 participants, 48 
were students from our university methods courses and 11 were nationally distributed in-service teachers at an NCTM workshop presented only once.

\section{Quantitative Assessment Results}

Identical quizzes were administered before and after the activity to all students, which includes the teachers at the workshop. Table 2 shows the percent of students $(N=59)$, who answered each question correctly on the first quiz (Column 2) and on the second quiz (Column 3).

Table 2

\begin{tabular}{|c|c|c|}
\hline Assessment Question & $\begin{array}{l}\text { \% Answering } \\
\text { Correctly on } \\
1^{\text {st }} \text { Quiz }\end{array}$ & $\begin{array}{l}\text { \% Answering } \\
\text { Correctly on } \\
2^{\text {nd }} \text { Quiz } \\
\end{array}$ \\
\hline $\begin{array}{l}\text { Describe what an electronic resistor } \\
\text { does. }\end{array}$ & 29.1 & 77.2 \\
\hline $\begin{array}{l}\text { State the standard unit of resistance, } \\
\text { ohms, as a symbol. }\end{array}$ & 80.0 & 100.0 \\
\hline $\begin{array}{l}\text { Calculate \% error in a written } \\
\text { problem. }\end{array}$ & 52.7 & 88.7 \\
\hline $\begin{array}{l}\text { State the minimum number needed for } \\
\text { a statistical analysis. }\end{array}$ & 41.8 & 84.1 \\
\hline Define the term "range." & 89.1 & 95.4 \\
\hline Define the term "mean." & 94.5 & 97.7 \\
\hline Define the term "standard deviation." & 78.1 & 79.5 \\
\hline $\begin{array}{l}\text { Define the term "relative standard } \\
\text { deviation }(\% \mathrm{RSD}) \text {." }\end{array}$ & 21.8 & 52.3 \\
\hline
\end{tabular}

On all questions, students showed an overall increase in both scientific and mathematical factual knowledge. The students participating in this activity gained knowledge while learning mathematics in the context of science.

\section{Qualitative Assessment Results}

The qualitative analysis was conducted using the project papers as an indicator of QL skills. In designing a rubric, the authors looked to recent publications in guiding them to examine QL skills:

[Educators need to] ...move away from a fragmented teaching and learning approach to a more holistic one. In particular we need to offer more opportunities for students to make decisions that involve information gathering and assessment, quantitative analysis, and 
communications about quantitative topics, not merely textbook calculations that use mathematics (Taylor 2008).

and

Lutsky makes the distinction between the interpretation of quantitative information (itself a challenge for many students) and using quantitative information in the support of an argument. He argues strongly that the latter approach can be a powerful and successful cross-curricular way to teach QL (Mast 2009).

Papers were scored from 0 to 5 points, 0 representing no paper being turned in and 5 being an exemplary paper (Table 3). The in-service teachers at the workshop did not have time to complete the project. Therefore, the number of students completing the project dropped to 48. In addition, since pre-service teachers had worked in groups during the activity, we asked them to work in pairs on the project. Therefore, only 24 projects were assessed.

\section{Table 3}

\section{Project Rubric}

\begin{tabular}{cl}
\hline Points Qualities of the Project (written paper) \\
\hline 5 & An argument is clearly stated. The argument is both explained and supported using \\
all four of the following criteria: the science of resistors, the experimental statistical \\
data, at least one appropriate graph, and the pricing of the resistors with a source \\
included and cited. The paper shows a clear understanding of the situation and \\
presents a convincing argument. The paper goes above and beyond the requirements \\
in some way, such as including additional cited information, graphs, tables, and/or \\
other visuals from cited researched sources. The paper is typed, contains few or no \\
errors in grammar, spelling, and/or punctuation, and is easy to read. The paper could \\
be considered exemplary. \\
An argument is clearly stated. The argument is both explained and supported using \\
all four of the following criteria: the science of resistors, the experimental statistical \\
data, at least one appropriate graph, and the pricing of the resistors with a source \\
included and cited. The paper shows a clear understanding of the situation and \\
presents a convincing argument. The paper goes does not go above and beyond the \\
requirements in any way. The paper is typed, contains some errors in grammar, \\
spelling, and/or punctuation, but is still easy to read. The paper could be considered \\
superior, yet, lacks the extra effort shown by an exemplary paper. \\
An argument is stated. The argument is both explained and supported using at least \\
three of the following four criteria: the science of resistors, the experimental \\
statistical data, at least one appropriate graph, and the pricing of the resistors with a \\
source included and cited. The paper shows an adequate understanding of the \\
situation and presents an adequate argument. The paper is typed, contains errors in \\
grammar, spelling, and/or punctuation, but is still readable. The paper could be \\
considered adequate. \\
An argument may not be stated. The paper contains some explanation and support \\
for the stated or intended argument using at least two of the following four criteria: \\
the science of resistors, the experimental statistical data, at least one appropriate \\
graph, and the pricing of the resistors with a source included and cited. The paper
\end{tabular}


may not show an adequate understanding of the situation and/or present an adequate argument. The paper goes does not go above and beyond the requirements in any way. The paper is typed, contains errors in grammar, spelling, and/or punctuation, and is difficult to read as a whole. The paper could be considered inadequate.

1 The paper was completed and turned in. The paper has very little merit. The paper could be considered unacceptable.

0 The paper was not turned in.

Table 4 shows the number of projects earning each score according to the rubric. We read and scored the papers independently and then compared scores. We agreed on 16 of the papers. For the remaining eight papers, we were within one point, so we reread these papers together and assigned an agreed-upon score.

Table 4.

Project Results $(N=24)$

\begin{tabular}{ll}
\hline Score & Number \\
\hline 5 (Exemplary) & 4 \\
4 (Superior) & 5 \\
3 (Adequate & 6 \\
2 (Inadequate) & 5 \\
1 (Unacceptable) & 3 \\
0 (No paper) & 1 \\
\hline
\end{tabular}

Following are two excerpts, one from an exemplary project and one from an adequate project:

Excerpt 1. Searching for the manufacturer's online price for resistors, we found that $5 \%$ resistors cost more than $10 \%$ resistors. We argue that manufacturers are simply separating out the more precise resistors and painting a gold band on them, 5\%. Looking at one of the largest online retailers, Digikey.com, we looked up several carbon composition resistors at both $10 \%$ and $5 \%$. $56 \Omega$ resistors had the following prices:

- $5 \%$ error $\rightarrow \$ 0.1040$ per resistor

- $10 \%$ error $\rightarrow \$ 0.0976$ per resistor

By selecting out the more precise group of resistors, the manufacturer can make $\$ 0.0064$ more per resistor. This doesn't sound like much money until you consider it as an increase of $6.56 \%$ profit!

In this excerpt, students used quantitative evidence to explain the difference between the experimental and painted color code by stating that $5 \%$ resistors are more expensive than $10 \%$ resistors. This is an exemplary argument because students realized that profit per resistor is a key factor for the manufacturer, thus, 
integrating the results of their experiment with every day, real-world experience. These students then calculated the increase in profit between selling a 5\% and a $10 \%$ resistor, which earned them a score of exemplary for going above and beyond. These students could have gone further by asking the question, "Why not sell the resistors at a higher price at $60 \Omega \pm 5 \%$ ?" However, researching the sale of resistors, they would have found that resistors are mass-produced in batches labeled $47 \Omega, 56 \Omega$, and $68 \Omega$, but not $60 \Omega$. In other words, these students would be heading for the interpretation that manufactured batches with resistors within $5 \%$ of the 56- $\Omega$ target are labeled with gold bands, and batches with resistors more than $5 \%$ but less than $10 \%$ away from the $56-\Omega$ target are labeled with silver bands.

Excerpt 2. We argue that manufacturers are saving money by placing less graphite carbon in the resistors and more silica sand. We know that less graphite means a higher resistance value. Looking online for the cost of graphite carbon and silica sand, we found the following information at Sigma Aldrich (a chemical ordering company):

- $\quad 99.99 \%$ pure graphite costs $\$ 133.50 / 113.4 \mathrm{~g}$ or $\$ 1.177 / \mathrm{g}$

- $\quad 99.8 \%$ pure silica sand cost $\$ 20.82 / 100 \mathrm{~g}$ or $\$ 0.208 / \mathrm{g}$

It takes less carbon to make a $59.6 \Omega$ resistor than $56 \Omega$ resistors. Even though the color painted on the resistor is blue, black, black and silver, $\left(56 \times 10^{\circ} \Omega\right)$, the manufacturer is saving money on the more expensive graphite.

In this excerpt, students attempted to resolve the discrepancy between the experimental and painted color code by stating that graphite is more expensive than silica sand. Students integrated their knowledge of chemistry with the cost of manufacturing a carbon composite resistor since using more graphite means that the resistor should cost more. However, students did not carefully look at the price of a $560 \Omega \pm 10 \%$ resistor, which is exactly the same price as a $56 \Omega \pm 10 \%$. If more graphite means more expense, then a resistor of more resistance would theoretically cost less to manufacture and should cost less to the consumer. Perhaps the savings are not passed to the consumer, but the students did not state this in their paper. They received a grade of "adequate" for integrating chemistry and quantitative evidence to support their argument, but did not score exemplary for their failure in recognizing more resistance would actually cost less.

In this section, we have discussed the results of two types of assessments that were given to the students. The first assessment was a quiz of factual mathematical and scientific knowledge acquired as a result of participating in the activity. The quizzes showed that the students' knowledge improved (Table 2). The second assessment measured the ability of the students to produce a logical, 
written explanation involving their study of resistors. After assessing 24 students, it was determined that more than $60 \%$ of the papers were adequate or better (Table 4).

\section{Concluding Remarks}

We began engaging pre- and in-service teachers in the activity described here to provide them with an experience that integrated mathematics, science, and communication with a real-world context being the "glue" that held the three areas together. As we sought a theoretical framework for the activity and its implications to the education of future teachers, we encountered people and literature that brought to light the QL-enhancing components of this activity.

We have become convinced that QL can be integrated into existing curricula. In the beginning, we wanted to increase students' mathematical knowledge of statistics and scientific knowledge of electronics as related to chemistry. In the past, at the end of the activity, it was easiest for us, as instructors, to simply explain the discrepancy in the resistor data to our students. However, we soon realized that the activity would be more powerful for the students if we gave them the opportunity to unravel the discrepancy for themselves. The activity has evolved such that students acquire data and arrive at a cognitive conflict. Then students synthesize knowledge and skills gained from the activity with research and communication to explain the discrepancy. In essence, this activity has been transformed from a teacher-based stand-and-deliver activity to a cooperative, student-based QL-enhanced activity. We believe that other interested educators can use the example activity described in this article as a template to design their own QL activities.

We realize that there are barriers to designing and implementing integrated QL-enhanced activities. One barrier is the time and effort required to either design or refine activities. A second is finding experts in various disciplines who are willing and able to come together in the pursuit of the task. From our experience, QL-enhanced activities are nearly impossible to develop without an interdisciplinary team. Working as a team, we approached this activity from two different perspectives, which led to deeper discussions resulting in a more powerful activity. Reflecting back upon our five-year experience, we believe that teamwork is the key to designing multifaceted, high-quality activities. A third barrier includes analyzing formative feedback from real students who help us to illuminate the differences and similarities between the disciplines of mathematics and science. Finally, a fourth barrier is summative assessment. We look to the National Numeracy Network and the readership of Numeracy to help us find researchers with common interests and the expertise in assessment to assist us in obtaining, refining, implementing, and interpreting summative assessment 
instruments. The need to acquire valid and reliable assessment data on the effects of QL-enhanced activities is imperative.

We hope that the drive to incorporate QL into classrooms across the country will not be like the one-sided cell phone conversation reported at the beginning of this article. Let us open the conversation for all to hear and engage in. As the instructors of the activity presented here, we are proud of the progress our preservice mathematics and science teachers have made and hope that they will incorporate their blossoming QL skills as they enter both the ranks of professional educators and as contributing, thinking members of our society. We anticipate that the next time each of them pulls out their cell phone, they may ask, "So, what was the cost of the resistors in this device? What science and mathematics is behind the functioning and pricing of those resistors?"

\section{Acknowledgements}

The authors would like to thank Central Washington University students, staff, and faculty for assistance with technical drawings and proof reading of chemistry and mathematics content (Michael Anderson, Stuart Boersma, Tony Brown, Anthony Diaz, Laura Skanse, and Mari Sorey). There were also many reviewer comments from this journal which helped form the final draft of this manuscript.

\section{References}

Boersma, S. and T. Willard. 2008. False positives and referral bias: Content for a quantitative literacy course. Numeracy. 1(2), Article 5. http://dx.doi.org/ $\underline{10.5038 / 1936-4660.1 .2 .5}$

Brown, T., H. LeMay, and B. Bursten. 1999. Chemistry: The central science, $8^{\text {th }}$ ed. Upper Saddle River, NJ.: Prentice Hall.

Bruner, J. 1960. The process of education. Cambridge, MA: Harvard University Press.

Hill, W. and P. Horowitz. 1989.The art of electronics, $2^{\text {nd }}$ ed. Cambridge: Press Syndicate of the University of Cambridge.

Madison, B. and L. Steen. 2008. Evolution of Numeracy and the National Numeracy Network. Numeracy. 1(1), Article 2. http://dx.doi.org/ 10.5038/1936-4660.1.1.2

Mast, M. 2009. Review of Calculations vs. Context: Quantitative Literacy and Its Implications for Teacher Education by Bernard L. Madison and Lynn Arthur Steen (Editors), Numeracy. 2(2), Article 6. http://dx.doi.org/10.5038/ 1936-4660.2.2.6 
NCTM (National Council of Teachers of Mathematics). 2000. Principles and standards for school mathematics. Reston, VA: National Council of Teachers of Mathematics.

Nelson, G. and L. Steen. 2003. Quantitative literacy: A science literacy perspective. Proceedings of the National Forum on Quantitative Literacy held at the National Academy of the Sciences, ed. B. Madison and L. Steen, 179-178. National Council on Education and Disciplines, Princeton, New Jersey.

Pienta, N. and J. A. Amend. 2005. Chemists' guide to effective teaching. In Electronic data to promote effective learning during laboratory activities, ed. Pienta, Chap. 14. Upper Saddle River, NJ: Pearson Prentice Hall.

Skoog, D., F. Holler, and T. Nieman. 1998. Principles of instrumental analysis, $5^{\text {th }}$ ed. Philadelphia, PA: Saunders College Publishing.

Sorey, T.L. and J. A. Amend. 2005. A research-based approach to solving problems in general chemistry, In Preparing future science and mathematics teachers: Faculty write about CETP innovations on campuses today, ed. D. Smith and E. Swanson 58-61. National Science Foundation, Division of Undergraduate Eduation, Collaborative for Excellence in Teacher Preparation (CETP).

Taylor, C. 2008. Preparing students for the business of the real (and highly quantitative) world. In Calculation vs. context: Quantitative literacy and its implications for teacher education, ed. B. L. Madison and L.A. Steen, 109-124. http://www.maa.org/q1/cvc/cvc-109-124.pdf

Vygotsky, L.S. 1962. Thought and Language. Cambridge, MA: MIT Press. http://dx.doi.org/10.1037/11193-000

Wilkins, J. 2000. Preparing for the $21^{\text {st }}$ century: The status of quantitative literacy in the United States. School Science and Mathematics, 100(8): 405-418. http://dx.doi.org/10.1111/j.1949-8594.2000.tb17329.x 